\title{
EL TRATAMIENTO DE LAS ETIMOLOGÍAS POR GRAMÁTICOS Y POETAS LATINOS
}

\begin{abstract}
It is traditionally asserted that there is an enormous difference between the treatment of the etymology given by the ancient tradition and the one of modern Linguistics. In this paper the authoress tries to tinge this assertment pointing out to some Latin grammarians, specially Varro, who forebode contemporary scientific formulations. However, the poets use the etymology just as a rhetorical "ornament».
\end{abstract}

Ha llegado a ser casi un tópico el afirmar que, entre el tratamiento de la etimología realizado por la antigüedad y el de la ciencia moderna, existe un verdadero abismo. De un modo bastante generalizado se oponen los términos etimología antigua y etimología moderna, entendiendo por antigua desde la civilización grecolatina hasta el siglo XIX exclusive.

La oposición entre una y otra se describe sintéticamente diciendo que es en el siglo XIX cuando la etimología ha comenzado a ser una ciencia con métodos propios y vinculada definitivamente a la lingüística. Hasta este momento la etimología se debía considerar más como arte que como ciencia, y como arte vinculado a la invención y lleno de arbitrariedades. En este marco hay que situar las palabras de Pedersen:

The ancient world bequeathed to Europe a legacy heavy with misunderstanding of the history of language ${ }^{1}$.

La opinión de Pedersen, fundamentalmente cierta, ha sido un obstáculo para llegar a percibir una serie de intuiciones de los autores antiguos, que podrían considerarse en cierto modo precedentes de formulaciones científicas actuales. Estas intuiciones se dan no sólo en el terreno de la etimología, sino en otros muchos ámbitos de la lingüística. Sería interep. 4.

1 The discovery of language, trad. ingl. de J. Webster Spargo, Bloomington 1962, 
sante, por tanto, ir desvelando progresivamente esos atisbos de método científico en los diferentes campos, pero en este artículo me voy a ceñir al ámbito etimológico, refiriéndome concretamente a los autores latinos más significativos en relación a este tema.

Entre los latinos la búsqueda de las etimologías de las palabras estuvo vinculada a la gramática y a la retórica, pero es solamente en el terreno de la teorización gramatical donde se pretende llegar a formular un incipiente método lingüistico que posibilite la sistematización de estas búsquedas etimológicas.

En Roma puede decirse que es con Varrón con quien se inician los estudios etimológicos desde una perspectiva que podríamos llamar científica. Por supuesto que otros gramáticos anteriores se ocuparon de cuestiones etimológicas; recuérdese, por ejemplo, a Elio Estilón, hombre doctísimo que debió ocuparse ampliamente de etimologías y a quien el mismo Varrón cita reprochándole explicar desde el latín palabras de origen griego, o Nigidio Fígulo, quien defiende la existencia de una gran armonía de sonido y sentido entre el nombre y la cosa nombrada. Pero es Varrón el primero que propiamente se plantea en Roma la elaboración de un cierto método etimológico.

Evidentemente en el mismo Varrón se perciben clarísimas influencias estoicas, pero en muchas ocasiones se deja llevar de su intuición personal y realiza su propia reflexión y sintesis de los rasgos de la lengua latina.

Bien es verdad que Varrón aporta numerosas etimologías que hoy resultan ingenuas o disparatadas a la luz de la ciencia lingüística; recuérdense, por ejemplo, entre otras: 'arma' ab arcendo, quod his arcemus hostem, 'gladium' $C$ in $G$ commutato a clade, quod fit ad hostium cladem gladium, origo potionis 'aqua', quod aequa summa. Pero, a pesar de estas «deficiencias», Varrón aporta un gran cúmulo de intuiciones lingüísticas en el ámbito de la etimología. Y es en estas intuiciones, con vistas a la creación de un método etimológico, donde me voy a detener especialmente.

Un primer avance en este camino de aproximación al método lingüistico lo constituye el hecho de que Varrón empiece a liberarse de los presupuestos estoicos, que buscaban la esencia de cada cosa bajo el nombre de ella, vinculando en cierta manera la etimología a la filosofia. Frente a este etimologismo excesivo Varrón llega a afirmar que el que encuentra las derivaciones correctas que relacionan equitatus con equites, equites con equus, y no dice de dónde procede equus, hace ya mucho por la ciencia (cf. L.L. VII 4). De donde se deduce que valoraba más los aspectos estrictamente lingüisticos que la insistente búsqueda de la esencia de las cosas.

Por otra parte, Varrón es absolutamente consciente de la amplitud de la problemática que plantea la búsqueda del origen de las palabras, de tal 
manera que llega a hacer una enumeración casi exhaustiva de las dificultades de esta búsqueda. Y así alude a la extinción frecuente de formas primitivas, a errores y alteraciones de las palabras en uso, a la introducción en la lengua vernácula de préstamos extranjeros, a los desplazamientos de sentido, etc.:

Quae ideo sunt obscuriora, quod neque omnis impositio uerborum extat, quod uetustas quasdam deleuit, nec quae extat sine mendo omnis imposita, nec quae recte est imposita, cuncta manet (multa enim uerba litteris commutatis sunt interpolata), uerbis, et multa uerba aliud nunc ostendunt, aliud ante significabant, ut 'hostis': nam tum eo uerbo dicebant 'peregrinum' qui suis legibus uteretur, nunc dicunt eum quem tum dicebant 'perduellem' ( $L . L$. V 3).

Vetustas pauca non deprauat, multa tollit. Quem puerum uidisti formosum, hunc uides deformem in senecta... Non mediocres enim tenebrae in silua ubi haec captanda neque eo quo peruenire uolumus semitae tritae (L.L.V 5).

De estas afirmaciones deducimos que Varrón se plantea la necesidad de hacer una biografia de la palabra (lo cual está en la base de los métodos etimológicos modernos), y para ello habría que estudiar los cambios fonéticos (multa enim uerba litteris commutatis sunt interpolata), los cambios semánticos (multa uerba aliud nunc ostendunt, aliud ante significabant), los préstamos incorporados a la lengua que se estudia (neque omnis origo est nostrae linguae e uernaculis uerbis), e incluso podríamos interpretar que Varrón alude a las transformaciones que puede acarrear la creación de una etimología popular (nec < impositio uerborum > quae extat sine mendo omnis imposita).

Todos estos temas son los que tiene planteados la ciencia etimológica actual, y, si bien es verdad que Varrón no acierta a dar soluciones adecuadas, sí fue muy lúcido en el planteamiento amplio de los problemas.

El método etimológico que Varrón llega a crear intenta estudiar las palabras clasificándolas en una especie de campos semánticos sobre los conceptos de espacio y tiempo. Esta agrupación se inspira en los principios de oposición de contrarios de Pitágoras, pero también aquí se presagian modernas metodologías, ya que del estudio de palabras agrupadas por campos semánticos la ciencia lingüística actual está obteniendo luminosos resultados. Varrón descubrió certeramente el interés de estas asociaciones cuando habla de la necesidad de perseguir las raices de las palabras hasta dondequiera que se extiendan:

Sed qua cognatio eius erit uerbi quae radices egerit extra fines suas persequemur. Saepe enim ad limitem arboris radices sub uicini prodierunt segetem (L.L. V 13). 
En cuanto a la creación de nuevas palabras es interesante también una afirmación suya que puede orientar las búsquedas del origen de palabras de nueva creación: sólo cuando una cosa pasa a ser usada por el hombre se siente la necesidad de designarla, por tanto para conocer el origen de las palabras necesitamos conocer la Historia, ya que este conocimiento no puede llegarnos más que por la tradición.

Ad haec dicimus, omnis orationis quamuis res naturae subsit, tamen si ea in usu non peruenerit, eo non peruenire uerba: ideo equus dicitur et equa: in usu enim horum discrimina; coruus et corua non, quod sine usu id, quod dissimilis naturae. Itaque quaedam aliter olim ac nunc: nam et tum omnes mares et feminae dicebantur columbae, quod non erant in eo usu domestico quo nunc, et nunc contra, propter domesticos usus quod internouimus, appellatur mas columbus, femina columba (L.L. IX 56).

Ad illud genus, quod prius, historia opus est (L.L. VIII 6).

Este tipo de asertos abren el campo de la lingüistica al concurso de otras disciplinas, presagiando las modernas concepciones de la lengua como fenómeno social.

Pero a pesar de este intento de Varrón de crear un método etimológico de carácter ya más estrictamente lingüístico, la influencia estoica de vincular el nombre a la esencia de la cosa sigue presente en los autores latinos, de tal manera que Cicerón traduce 'etimología' por ueriloquium, subrayando el aspecto de búsqueda de la verdad, y por notatio, insistiendo en el aspecto de signo que la palabra tiene con respecto a la cosa significada. Cicerón creyó además que el nombre propio designa los atributos o cualidades de la persona. Por su parte Quintiliano retomó esta opinión con la única limitación de referir este tipo de designación sólo a títulos de honor como Sapiens, Magnus, Pius, etc.

Las etimologías de base estoica tuvieron una importancia fundamental en la Edad Media, gracias a la obra de S. Isidoro de Sevilla. Los Etymologiarum libri pueden considerarse obra básica de este período.

Claramente expresa S. Isidoro su vinculación con el estoicismo cuando afirma:

Nam dum uideris unde ortum est nomen, citius uim eius intellegis. Omnis enim rei inspectio etymologia cognita planior est (Etym. I 29).

Pero se observa ya una cierta limitación a este principio estoico en las siguientes afirmaciones:

Non autem omnia nomina a ueteribus secundum naturam imposita sunt, sed quaedam et secundum placitum, sicut et nos seruis et possessionibus interdum secundum quod placet nostrae uoluntati nomina damus (Etym. I 29). 
A pesar de las dificultades que señala, Isidoro trata de hallar un método en la búsqueda etimológica, y así afirma que los tipos principales de etimologías son tres: ex causa, como "reges" a regendo et recte agendo, ex origine, como "homo" quia sit ex humo, y e contrariis, como "lucus», quia umbra opacus parum luceat. $\mathrm{E}$ incluso, centrándose en los procedimientos de derivación gramatical, distingue una derivación de los nombres de una derivación de los sonidos y apunta la necesidad de diferenciar las palabras de procedencia griega:

Quaedam etiam facta sunt ex nominum deriuatione, ut a prudentia «prudens"; quaedam etiam ex uocibus, ut a garrulitate "garrulus»; quaedam ex Graeca etymologia orta et declinata sunt in Latinum, ut «silua», «domus» (Etym. I 29).

De hecho, al analizar las palabras que estudia Isidoro, vemos etimologías relacionadas con los tres tipos descritos y que incluso desbordan estos tipos, ya que emplea además procedimientos de interpretación popular, filosófica, gramatical e incluso teológica ${ }^{2}$. Por supuesto que este incipiente método tiene muchas limitaciones: la mezcla indiscriminada de procedimientos, la arbitrariedad en la aplicación de ellos, el predominio de los procedimientos filosóficos sobre los lingüísticos, etc.

$\mathrm{Y}$ es precisamente por la influencia de $\mathrm{S}$. Isidoro principalmente por lo que siguen vigentes en la Edad Media las etimologias de base estoica, y así, por elegir uno entre los numerosos testimonios de la época, recordemos cómo Petrus Helie, ya en el siglo IX, al definir la etimología en su Summa Grammaticae, insiste una vez más en la relación entre la palabra y la realidad de la cosa, aunque teniendo también en cuenta el parecido de las letras. Al insistir en la etimología como ueriloquium, Petrus Helie no hace otra cosa que recoger el estado de la cuestión en su época.

Por otra parte, como ya dije al-principio, la etimología se encontraba vinculada desde una época muy antigua a la retórica y se empleaba en poesía como una especie de recurso ornamental.

Interpretaciones más o menos acertadas de nombres propios las encontramos, por ejemplo, en Virgilio. Pero es con Ovidio con quien comienzan las interpretaciones disparatadas que tan populares serán después en la Edad Media (recuérdese por ejemplo las etimologías que propone para Agonalia: agatne, agantur o Agnalia, ofreciendo para ellas unas explicaciones totalmente en contradicción con la lingüistica (cf. Fastos I 317 ss.).

2 Cf. M.C. Díaz y Díaz, "Introducción general» a las Etimologias de S. Isidoro de Sevilla, Madrid 1982, pp. 186-188. 
En la Edad Media este tipo de etimologías proliferan extraordinariamente, de tal manera que la explicación de los nombres propios fue un «adorno» indispensable en la poesía. Sirva de ejemplo, a título de curiosidad, la explicación que el poeta Abón da del nombre de París, por su parecido con la ciudad griega Isia, por supuesto desconocida: Isie quasi par ${ }^{3}$.

Evidentemente desde la vinculación de la etimología a la retórica no se produce ningún avance hacia la creación del método lingüístico, que tan intuitivamente preludió Varrón. Pero sí creo que se puede afirmar que desde el campo de la teorización gramatical en la Antigüedad, con Varrón a la cabeza, se va formando un caldo de cultivo que, unido a los avances renacentistas, posibilitará el nacimiento de un método estrictamente lingǘstico en el siglo xIx y su ulterior desarrollo en el xx.

Ciriaca Morano

${ }^{3}$ Bella Parisiacae Vrbis I 9 ( MGH, Poetae Latini Aeui Carolini, IV I, Berlín 1964, p. 79). 